\title{
Prevalence and association of vitamin $D$ deficiency and mortality in patients with severe sepsis
}

\author{
Konlawij Trongtrakul' \\ Chookiat Feemuchang ${ }^{2}$ \\ 'Critical Care Division, Emergency \\ Medicine Department, ${ }^{2}$ Internal \\ Medicine Department, Faculty \\ of Medicine Vajira Hospital, \\ Navamindradhiraj University, Bangkok, \\ Thailand
}

\author{
This article was published in the following Dove Press journal: \\ International Journal of General Medicine \\ 8 November 2017 \\ Number of times this article has been viewed
}

Background: Vitamin D is a steroid prohormone that regulates body calcium and phosphate metabolism. Recent studies have shown an association between low vitamin D status and high mortality in patients admitted to intensive care units. To date, there are limited data available specifically about severely septic patients in medical units.

Objectives: To determine the prevalence of vitamin D deficiency in severely septic patients and its clinical outcomes, including mortality rate.

Methods: A prospective observational study was conducted to investigate the prevalence of vitamin D deficiency and its association with 30-day mortality in patients with severe sepsis. Patients admitted to medical wards at our hospital between November 2014 and March 2015 were included in the study. A 25 -hydroxyvitamin D level $<20 \mathrm{ng} / \mathrm{mL}$ was defined as vitamin D deficiency, and $<12 \mathrm{ng} / \mathrm{mL}$ as severe deficiency. For an association analysis, the patients were grouped into deficient versus not deficient and severely deficient versus not severely deficient. Results: One hundred and ten eligible patients were enrolled. A total of 83 patients $(75 \%)$ had vitamin D deficiency and 42 (38\%) had severe deficiency. Despite an insignificant higher 30-day hospital mortality rate in vitamin D deficient versus non-deficient groups ( $16 \% \mathrm{vs} 4 \%, p=0.18$ ), the differences were significant between the severely deficient versus non-severe groups $(23 \%$ vs $4 \%, p=0.02)$. The odds ratio of the 30-day mortality rate was 4.83 (95\% confidence interval $[\mathrm{CI}], 0.60-38.77, p=0.14)$ for vitamin D deficiency and 7.69 (95\% CI, 2.00-29.55, $p=0.003)$ for severe deficiency.

Conclusion: The prevalence of vitamin D deficiency was very high in three-quarters of patients with severe sepsis. A significant higher mortality rate was observed, particularly in patients with severe vitamin D deficiency.

Keywords: vitamin D deficiency, 25-hydroxyvitamin D, severe sepsis, medical unit, mortality rate

\section{Introduction}

Vitamin D is one of the most important steroid prohormones. Its main function is to regulate calcium and phosphate metabolism, and bone homeostasis. Moreover, it is also involved in other physiological systems, for instance, cellular gene transcription, ${ }^{1}$ anti-inflammation, ${ }^{2}$ antiproliferation, ${ }^{2}$ and cellular immune response to infection. ${ }^{3}$

Some experiments on vitamin D supplementation in critically ill patients demonstrated that vitamin D can suppress inflammatory cytokines (such as interleukin-6 and C-reactive protein), ${ }^{4}$ augment anti-inflammatory mediators (such as interleukin-10), ${ }^{5}$ and act as an antibacterial peptide (such as cathelicidin). ${ }^{5,6}$ Vitamin D deficiency, usually represented as a low serum concentration of 25-hydroxyvitamin $\mathrm{D}(25(\mathrm{OH}) \mathrm{D})$, has
Correspondence: Konlawij Trongtrakul Critical Care Division, Emergency Medicine Department, Faculty of Medicine Vajira Hospital,

Navamindradhiraj University, 68I Samsen Road, Dusit District, Bangkok, Thailand 10300

Tel +66819928133

Fax +6626687050

Email konlawij@live.com 
been found to be associated with an increased risk of morbidities, such as infection, ${ }^{7-10}$ acute kidney injury, ${ }^{11}$ myocardial infarction, ${ }^{12}$ etc. Its incidence ranged from $38 \%$ to $93 \%$ in critically ill patients. ${ }^{13-16}$ It also correlated with a longer stay in the intensive care unit ${ }^{17}$ and higher mortality rate. ${ }^{8,9,16,18}$

Theoretically, vitamin D supplementation for deficits should be clinically useful in patients with sepsis. However, many questions remain to be answered including the optimum dose of vitamin D administration, initiation time, and the most effective route. ${ }^{19}$ The most recent randomized clinical trial (VITdAL-ICU study) could not establish any benefit of vitamin D supplementation over placebo in all critically ill patients who had vitamin D deficiency, except in a certain group of patients. ${ }^{20}$ Patients who had very severe vitamin D deficiency, classified as a vitamin D level of $\leq 12 \mathrm{ng} / \mathrm{mL}$, had significantly lower mortality rates after receiving high dose vitamin D compared to placebo.

Data about vitamin D deficiency and the role of its replenishment are from Western countries where the sources of vitamin D, especially some kinds of food, sunlight exposure, habits of vitamin supplementation, or genetic variation may differ from other countries. Several studies from Asia, including Thailand, reported the prevalence of vitamin D deficiency; however, these studies were performed in healthy individuals. $^{21,22}$ There are limited data about the prevalence and impact of vitamin D deficiency among patients with critical illness.

\section{Objective}

The objective of this study was to assess the prevalence of vitamin $\mathrm{D}$ deficiency, measured by serum concentrations of $25(\mathrm{OH}) \mathrm{D}$, and the association with clinical outcomes especially mortality rate in Thai patients with severe sepsis.

\section{Methodology}

Our prospective cohort study was approved by the Ethical Committee for Research of the Faculty of Medicine Vajira Hospital (COA 096/57) before registration with the Thai Clinical Trials Registry (TCTR 20151130001). Informed consent was obtained from the patients or their legally authorized representatives. Inclusion criteria were patients admitted to our hospital between November 1, 2014 and March 31, 2015, aged at least 18 years old, with a clinical diagnosis of severe sepsis based on the Surviving Sepsis Campaign definition. ${ }^{23}$ Patients with end stage kidney disease, advanced stage cancer, older than 65 years with a history of repeated falling, pregnancy, a history of glucocorticoid use, or vitamin D supplementation were excluded.
A previous study by Venkatram et $\mathrm{al}^{16}$ reported $78 \%$ vitamin $\mathrm{D}$ deficiency in 437 patients in the medical intensive care unit. Based on this rate, we assumed a sample size of 104 cases was needed to demonstrate the prevalence of vitamin $\mathrm{D}$ deficiency in our study.

As a standard practice in our institution, all patients with a clinical diagnosis of severe sepsis were admitted to medical wards. After a thorough physical examination, routine laboratory investigations including complete blood count (CBC), blood chemistry, serum electrolytes, two-specimen hemoculture, site specific culture as indicated, and chest $\mathrm{X}$-ray were performed. Patients who met the inclusion criteria were assessed by one researcher $(\mathrm{CF})$ to evaluate the severity of illnesses by the Acute Physiology and Chronic Health Evaluation-II (APACHE-II) score at the same time. Additional laboratory tests among patients enrolled into the study were $25(\mathrm{OH}) \mathrm{D}$ and parathyroid hormone $(\mathrm{PTH})$ levels. The serum assay of $25(\mathrm{OH}) \mathrm{D}$ was studied by the electrochemical luminescent technique (Hitachi Cobas E 601; Roche Diagnostics, Indianapolis, IN, USA). Regular quality control of our laboratory instruments follows the Randox International Quality Assessment Scheme program. The variation coefficients of the assay control were $6.5 \%$ at $19.4 \mathrm{ng} / \mathrm{mL}$ and $9.5 \%$ at $39.1 \mathrm{ng} / \mathrm{mL}$.

All patients received empirical antibiotics upon diagnosis. The antibiotics were subsequently de-escalated according to the culture report. Other treatments were conducted at the discretion of attending physicians without any intervention from the researchers. All patients were followed up at least 30 days after a diagnosis of sepsis.

Clinical data collected were age, sex, body mass index (BMI), comorbidities, APACHE-II score, primary source of infection, endotracheal intubation rate, and duration of mechanical ventilation, length of hospital stay, and 30-day hospital mortality. Patients who were alive were censored after 30 days of follow-up. Laboratory data collected, aside from levels of $25(\mathrm{OH}) \mathrm{D}$ and $\mathrm{PTH}$, were $\mathrm{CBC}$, blood sugar, blood urea nitrogen, serum creatinine, serum electrolytes, lactate, albumin, calcium, and phosphate.

Vitamin D status, determined by serum 25(OH)D level, was defined according to the Endocrine Society guidelines: normal 25(OH)D level, at least $30 \mathrm{ng} / \mathrm{mL}$; insufficiency level, between 20 and $29.9 \mathrm{ng} / \mathrm{mL}$; and deficient 25(OH)D level, $<20 \mathrm{ng} / \mathrm{mL} .{ }^{3,24}$ For statistical comparison, we categorized the patients into two groups by their vitamin D level: not deficient (normal and insufficiency) versus deficient. In addition, we used a predefined definition for severe vitamin $\mathrm{D}$ deficiency when $25(\mathrm{OH}) \mathrm{D}$ level was $<12 \mathrm{ng} / \mathrm{mL}^{20}$ to categorize our 
patients into two groups as severely versus non-severely deficient for comparing additional analyses.

STATA statistical software version 13.0 (StataCorp LP, College Station, TX, USA) was used for statistical analyses. Discrete baseline characteristics were expressed as number and percentages, whereas continuous variables were expressed as mean \pm standard deviations or median \pm interquartile range (IQR1-IQR3). Data from patients with or without vitamin D deficiency were compared by chi-square or Fisher's exact test as appropriate for categorical data, and by Student's $t$-test or the Mann-Whitney $U$ test for continuous data. Kaplan-Meier survival function curve was generated and compared by log-rank test in each deficient value. Logistic regression analysis, adjusted by sex and illness severity using APACHE-II score, was carried out to identify an association between $25(\mathrm{OH}) \mathrm{D}$ level and the 30-day mortality. $p$-values $<0.05$ were considered statistically significant.

\section{Results}

During the study period, 114 patients met all inclusion criteria. However, serum samples of four patients were unavailable for $25(\mathrm{OH}) \mathrm{D}$ analysis. Thus, a total of 110 patients were enrolled in the study. We found vitamin D deficiency, 25(OH) D level $<20 \mathrm{ng} / \mathrm{mL}$, in 83 patients $(75 \%)$ and no vitamin D deficiency in 27 patients $(25 \%)$. The non-deficient group either had vitamin D insufficiency (17 patients) or normal vitamin D status (10 patients).

Table 1 demonstrates baseline characteristics according to vitamin D status: deficient or non-deficient groups. There was no significant difference between the two groups

Table I Characteristics of septic patients according to vitamin D deficient and severe vitamin D deficient status

\begin{tabular}{|c|c|c|c|c|c|c|}
\hline Baseline characteristics & $\begin{array}{l}\text { Vitamin D } \\
\text { deficient } \\
(<20 \mathrm{ng} / \mathrm{mL}) \\
(\mathrm{n}=83)\end{array}$ & $\begin{array}{l}\text { Not vitamin D } \\
\text { deficient } \\
(\geq 20 \mathrm{ng} / \mathrm{mL}) \\
(\mathrm{n}=27)\end{array}$ & p-value & $\begin{array}{l}\text { Vitamin D } \\
\text { deficient } \\
(<12 \mathrm{ng} / \mathrm{mL}) \\
(\mathrm{n}=53)\end{array}$ & $\begin{array}{l}\text { Not vitamin } D \\
\text { deficient } \\
(\geq 12 \mathrm{ng} / \mathrm{mL}) \\
(\mathrm{n}=57)\end{array}$ & $p$-value \\
\hline Age (years) & $59.3 \pm 15.3$ & $56.0 \pm 14.2$ & 0.32 & $61.3 \pm 13.6$ & $56.0 \pm 15.9$ & 0.07 \\
\hline Female (\%) & $50(60)$ & $6(22)$ & 0.001 & $28(53)$ & $28(49)$ & 0.70 \\
\hline Body mass index $\left(\mathrm{kg} / \mathrm{m}^{2}\right)$ & $21.90 \pm 3.68$ & $22.68 \pm 3.17$ & 0.34 & $21.79 \pm 3.76$ & $22.36 \pm 3.39$ & 0.42 \\
\hline APACHE-II score ${ }^{a}$ & $12(9-16)$ & $10(5-14)$ & 0.03 & $14(10-19)$ & $10(6-14)$ & 0.001 \\
\hline \multicolumn{7}{|l|}{ Comorbidities (\%) } \\
\hline I. Endocrinology system & $44(53)$ & $10(37)$ & 0.15 & $28(53)$ & $26(46)$ & 0.45 \\
\hline 2. Cardiology system & $44(53)$ & $10(37)$ & 0.15 & $29(55)$ & $25(44)$ & 0.26 \\
\hline 3. Neurology system & $13(16)$ & $3(I I)$ & 0.76 & $9(17)$ & $7(12)$ & 0.59 \\
\hline 4. Respiratory system & $5(6)$ & $2(7)$ & 1.00 & $4(8)$ & $3(5)$ & 0.71 \\
\hline \multicolumn{7}{|l|}{ Primary source of infection (\%) } \\
\hline I. Respiratory system & $24(29)$ & II (4I) & 0.25 & $17(32)$ & $18(32)$ & 0.99 \\
\hline 2. Systemic infection & $21(25)$ & $6(22)$ & 0.75 & $13(25)$ & $14(25)$ & 0.99 \\
\hline 3. Genitourinary system & $81(98)$ & $27(100)$ & 0.99 & $52(98)$ & $56(98)$ & 0.99 \\
\hline 4. Gastrointestinal system & $13(16)$ & $2(7)$ & 0.35 & $10(19)$ & $5(9)$ & 0.17 \\
\hline 5. Other systems & $5(6)$ & $4(15)$ & 0.20 & $2(4)$ & $7(12)$ & 0.16 \\
\hline \multicolumn{7}{|l|}{ Investigations } \\
\hline Blood urea nitrogen $(\mathrm{mg} / \mathrm{dL})^{\mathrm{a}}$ & $18(10-26)$ & $13(9-23)$ & 0.20 & $20(11-35)$ & $15(9-22)$ & 0.02 \\
\hline Creatinine $(\mathrm{mg} / \mathrm{dL})^{\mathrm{a}}$ & $0.86(0.71-1.22)$ & $0.81(0.62-1.17)$ & 0.43 & $0.87(0.74-1.20)$ & $0.85(0.67-1.17)$ & 0.59 \\
\hline Lactate $(\mathrm{mmol} / \mathrm{L})^{\mathrm{a}}$ & $2.7(1.8-4.1)$ & $1.9(1.6-4.0)$ & 0.48 & $2.7(1.7-3.5)$ & $2.5(1.7-4.4)$ & 0.78 \\
\hline Albumin $(g / d L)$ & $3.1 \pm 0.8$ & $3.2 \pm 0.5$ & 0.35 & $3.0 \pm 0.8$ & $3.3 \pm 0.7$ & 0.05 \\
\hline Calcium (mg/dL) ${ }^{\mathrm{a}}$ & $8.2(7.8-8.7)$ & $8.4(7.7-8.9)$ & 0.57 & $8.2(7.7-8.7)$ & $8.4(7.9-8.9)$ & 0.08 \\
\hline Phosphate (mg/dL) & $3.25 \pm 1.18$ & $3.21 \pm 1.04$ & 0.88 & $3.09 \pm 1.08$ & $3.37 \pm 1.19$ & 0.14 \\
\hline $25(\mathrm{OH}) \mathrm{D}(\mathrm{ng} / \mathrm{mL})$ & $9.8 \pm 4.8$ & $28.3 \pm 5.9$ & $<0.001$ & $6.9 \pm 3.0$ & $21.3 \pm 8.0$ & $<0.001$ \\
\hline Parathyroid hormone $(\mathrm{pg} / \mathrm{mL})^{\mathrm{a}}$ & $50.7(33.6-80.3)$ & $38.4(28.0-50.5)$ & 0.04 & $57.1(33.9-82.7)$ & $42.3(27.9-62.1)$ & 0.046 \\
\hline Hemoglobin $(\mathrm{g} / \mathrm{dL})$ & $10.8 \pm 2.6$ & $11.5 \pm 2.6$ & 0.25 & $10.8 \pm 2.8$ & $11.1 \pm 2.5$ & 0.33 \\
\hline White cell count $\left(10^{3} / \mu \mathrm{L}\right)^{\mathrm{a}}$ & $13.5(9.5-17.5)$ & $12.5(6.1-15.6)$ & 0.36 & $13.6(8.4-18.1)$ & $12.9(9.6-15.6)$ & 0.74 \\
\hline Platelet $\left(10^{3} / \mu \mathrm{L}\right)$ & $243.0 \pm 126.9$ & $216.3 \pm 165.5$ & 0.38 & $237.8 \pm 124.8$ & $235.1 \pm 148.6$ & 0.53 \\
\hline \multicolumn{7}{|l|}{ Outcomes } \\
\hline 30-Day hospital mortality (\%) & $13(16)$ & I (4) & 0.18 & $12(23)$ & $2(4)$ & 0.003 \\
\hline Length of hospital stay (days) & $16(7-19)$ & II (7-23) & 0.84 & II (7-25) & $14(7-19)$ & 0.88 \\
\hline Endotracheal intubation (\%) & $23(28)$ & $3(\mathrm{II})$ & 0.08 & $18(34)$ & $8(14)$ & 0.02 \\
\hline Duration of mechanical ventilation (days) ${ }^{\mathrm{a}}$ & $7(3-20)$ & $2(2-20)$ & 0.49 & $8(3-20)$ & $5(2-15)$ & 0.64 \\
\hline
\end{tabular}

Note: ${ }^{R}$ Reported in median (IQRI-IQR3); other data are reported as mean and SD, while discrete data are reported as number and percentages.

Abbreviations: APACHE-II score, Acute Physiology and Chronic Health Evaluation-II score; IQR, interquartile range; 25(OH)D, 25-hydroxyvitamin D. 
regarding age, BMI, comorbidities, and primary source of infection. Laboratory data including CBC, blood chemistry, and PTH levels are also shown in Table 1. We found three features which were significantly different between the two groups: sex, APACHE-II scores, and PTH levels. Vitamin D deficient patients were more likely to be female compared to the non-deficient group ( $60 \%$ vs $22 \%, p=0.001$ ), had higher APACHE-II scores (12; IQR, 9-16 vs 10; IQR, 5-14, $p=0.03$ ), and higher PTH levels (50.7 pg/mL; IQR, 33.6-80.3 pg/mL vs $38.4 \mathrm{pg} / \mathrm{mL}$; IQR, 28.0-50.5 pg/mL, $p=0.04)$.

Although worse clinical outcomes were found among patients who had vitamin D deficiency, the differences were not statistically significant (Table 1). Patients who had vitamin $\mathrm{D}$ deficiency had higher 30-day hospital mortality (16\% vs $4 \%, p=0.18)$, greater intubation rate $(28 \%$ vs $11 \%, p=0.08)$, longer duration of mechanical ventilation (7 days; IQR, 3-20 days vs 2 days; IQR, 2-20 days, $p=0.49$ ), and longer length of hospital stay (16 days; IQR, 7-19 days vs 11 days; IQR, 7-23 days, $p=0.84$ ) compared to patients with no deficiency. Table 2 shows the odds ratio (OR) of mortality was 4.83; $95 \%$ confidence interval $[\mathrm{CI}], 0.60-38.77, p=0.14$, and 5.05; 95\% CI, 0.57-44.61, $p=0.15$ after adjustment for covariates.

A comparison of severe vitamin $\mathrm{D}$ deficient patients with those who were not shows that the baseline characteristics were similar to previous $25(\mathrm{OH}) \mathrm{D}$ levels, except in a certain proportion of females (Table 1). Our study found that patients with severe deficiency had a significantly higher percentage of 30-day hospital mortality ( $23 \%$ vs $4 \%, p=0.003)$, endotracheal intubation ( $34 \%$ vs $14 \%, p=0.02)$, and worse survival (Figure 1). The OR of mortality was 7.69; 95\% CI, 2.00-29.55, $p=0.003$, and $6.11 ; 95 \%$ CI, $1.46-25.67, p=0.01$ when adjusted by sex and illness severity using APACHE-II score (Table 2). However, we could not demonstrate any differences between severe versus not severe deficiency regarding the length of hospital stay (11 days; IQR, 8-25 days vs 14 days; IQR, 7-19 days, $p=0.88$ ) and duration of mechanical ventilation ( 8 days; IQR, 3-20 days vs 5 days; IQR, 2-15 days, $p=0.64$ ) (Table 1).

\section{Discussion}

Despite being a country near the equator, located at latitudes between $5^{\circ} 30 \mathrm{~N}$ and $20^{\circ} 30 \mathrm{~N}$, with high sunlight exposure, a national survey of healthy Thai people still reported a $6 \%$ prevalence of vitamin D deficiency. ${ }^{21}$ The rate was much higher in Bangkok than other areas, at $14 \%{ }^{21}$ In comparison, Western populations reported higher rates of vitamin D deficiency; for example, $32 \%$ in USA $^{25}$ and $41 \%$ in France. ${ }^{26}$

Our study found a high prevalence of vitamin D deficiency, at $75 \%$, in Thai patients with severe sepsis. This was nearly 13 times greater than that found in the normal Thai population, or about five times specifically in the population residing in Bangkok. Our finding was also within the range found in studies from Western countries (USA, France, and Australia), which reported prevalences of 38\%-93\% among critically ill populations. ${ }^{13-16}$

The wide range of prevailing rates reported in various studies may result from particular characteristics of the populations studied. Our study found that female sex, higher APACHE-II score, and higher PTH level were significantly associated with a higher prevalence of vitamin D deficiency. Previous studies have also demonstrated sex as an important risk for vitamin D deficiency; however, males carried a greater risk in other studies. ${ }^{16,18}$ This might be due to corresponding findings in a normal population where healthy Thai females had a three-fold greater prevalence of vitamin $\mathrm{D}$ deficiency than males. ${ }^{22}$ A possible explanation for this greater risk might be due to the tradition of women avoiding sun exposure or greater usage of sunblock devices and sunscreen among women than men. Significantly higher PTH levels were found in our patients with vitamin D deficiency; this was also reported in other studies by Nair et $\mathrm{al}^{27}$ and Chen et al. ${ }^{28} \mathrm{~A}$ physiological response of PTH increasing in response to lower levels of vitamin $\mathrm{D}$ could be the reason for this finding. ${ }^{29}$

We found only slightly higher 30-day mortality between vitamin $\mathrm{D}$ deficient and not deficient patients with severe

Table 2 Logistic regression analysis to identify the association of vitamin D status and 30-day hospital mortality

\begin{tabular}{|c|c|c|c|c|}
\hline & \multicolumn{2}{|c|}{ Univariate analysis } & \multicolumn{2}{|c|}{ Multivariable analysis } \\
\hline & OR (95\% CI) & $p$-value & OR (95\% Cl) & $p$-value \\
\hline Vitamin D deficient & $4.83(0.60-38.77)$ & 0.14 & $5.05(0.57-44.61)$ & 0.15 \\
\hline Female & $0.49(0.15-1.57)$ & 0.23 & $0.25(0.07-0.96)$ & 0.04 \\
\hline APACHE-II & $1.13(1.04-1.24)$ & 0.004 & $1.14(1.04-1.26)$ & 0.006 \\
\hline Severe vitamin $D$ deficient & $7.69(2.00-29.55)$ & 0.003 & $6.11(1.46-25.67)$ & 0.01 \\
\hline Female & $0.49(0.15-1.57)$ & 0.23 & $0.27(0.07-1.06)$ & 0.06 \\
\hline APACHE-II & $1.13(1.04-1.24)$ & 0.004 & $1.13(1.02-1.25)$ & 0.02 \\
\hline
\end{tabular}

Abbreviations: OR, odds ratio; $\mathrm{Cl}$, confidence interval; APACHE-II score, Acute Physiology and Chronic Health Evaluation-II score. 


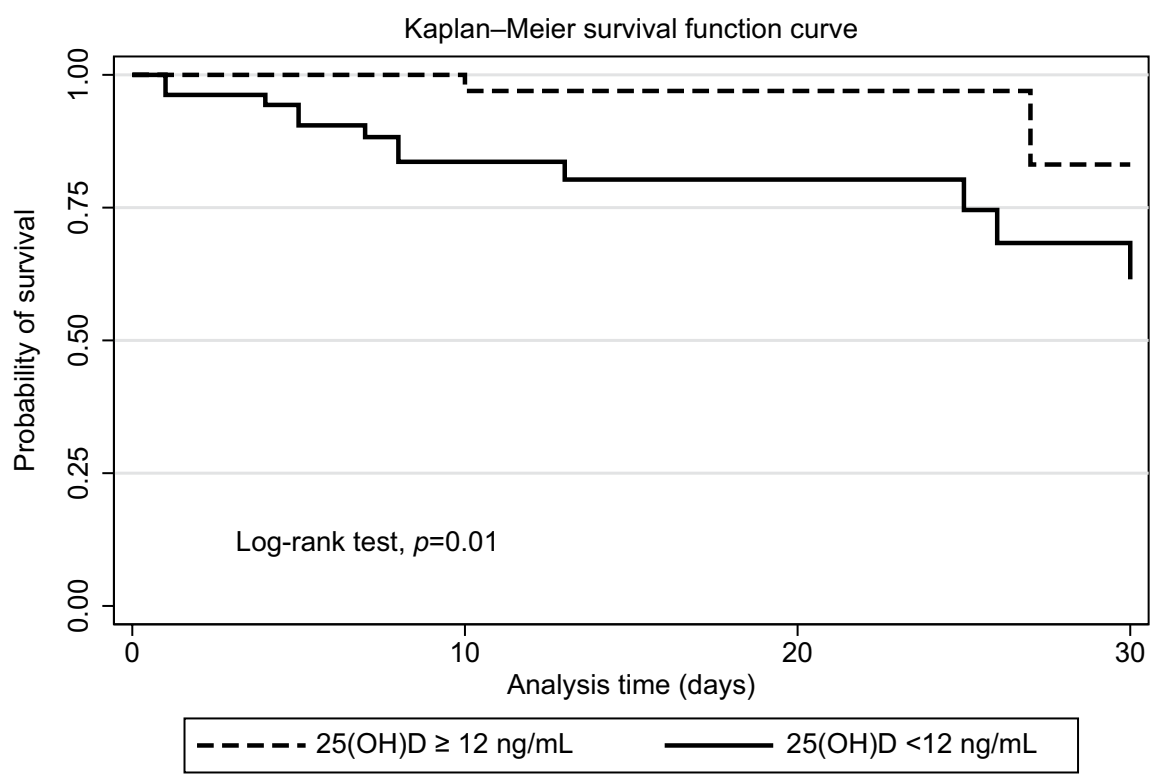

Figure I Kaplan-Meier curve for overall survival in septic patients with severe vitamin D deficiency, $25(\mathrm{OH}) \mathrm{D}$ level $<12 \mathrm{ng} / \mathrm{mL}$. Abbreviation: 25(OH)D, 25-hydroxyvitamin D.

sepsis in medical wards. Previous studies have shown inconsistent results regarding the mortality rate and vitamin D deficiency. Most studies showed a significant inverse association between vitamin D level and mortality. The ORs among vitamin D deficient patients were $1.81,{ }^{15}$ and 2.62 (95\% CI, $1.70-4.03, p<0.001)$ or 1.82 (95\% CI, $1.05-3.16, p=0.034)$ after adjusting for age and APACHE-II score. ${ }^{28}$ Another study of the FINNAKI cohort ${ }^{30}$ and our study could not demonstrate a significant association. The FINNAKI cohort found that vitamin $\mathrm{D}$ deficiency among patients admitted to the intensive care unit (ICU) was not associated with 90-day mortality (hazard ratio [HR] of $0.99 ; 95 \% \mathrm{CI}, 0.72-1.36) .{ }^{30}$ The severity of illness in each study may contribute to different findings. The patients in our study had low overall illness with an APACHE-II severity score of only 11 which was much lower than 20-27 reported in other studies. ${ }^{13,28,30}$ Another possible reason was the sample size in our study which was calculated from the proportion of vitamin D deficiency. ${ }^{16}$ This might lead to inadequate statistical power to detect a difference in mortality at a $25(\mathrm{OH}) \mathrm{D}$ level $<20 \mathrm{ng} / \mathrm{mL}$. A larger sample size in a future study is needed to confirm this finding.

We found a significant association of higher 30-day mortality and levels of $25(\mathrm{OH}) \mathrm{D}<12 \mathrm{ng} / \mathrm{mL}$ which was used to classify severe deficiency. ${ }^{20}$ This was similar to the report from the FINNAKI cohort which found an association of $25(\mathrm{OH}) \mathrm{D}$ level with 90-day mortality $(\mathrm{HR}=0.44 ; 95 \% \mathrm{CI}$, $0.22-0.87, p=0.02$ ) when using a $25(\mathrm{OH}) \mathrm{D}$ level $<10 \mathrm{ng} / \mathrm{mL}$ to define severe deficiency. ${ }^{30}$
Our study could not demonstrate a relationship between length of hospital stay, intubation rate, and duration of mechanical ventilation of patients according to vitamin D deficiency status. Previous studies have demonstrated inconsistent findings regarding the length of hospital stay. Lucidarme et al ${ }^{13}$ and Venkatram et al, ${ }^{16}$ similar to our study, did not find any influence from vitamin D deficiency on the length of hospital stay, while McKinney et $\mathrm{al}^{15}$ found a twofold increase in length of ICU stay when patients had $25(\mathrm{OH})$ $\mathrm{D}<20 \mathrm{ng} / \mathrm{mL}$. Only one study by Venkatram et al ${ }^{16}$ evaluated and demonstrated the same finding as our study that vitamin D status had no significant impact on the intubation rate and duration of mechanical ventilation.

\section{Conclusion}

This study demonstrated a high prevalence of vitamin D deficiency in three-quarters of patients who had severe sepsis. A very low concentration of the $25(\mathrm{OH}) \mathrm{D}$ level was associated with higher 30-day hospital mortality especially when the $25(\mathrm{OH}) \mathrm{D}$ level fell below $12 \mathrm{ng} / \mathrm{mL}$.

\section{Strengths and limitations of this study}

Some limitations were recognized in our study. First, in sepsis, many reasons can explain the decrease in the level of vitamin $\mathrm{D},{ }^{19,31}$ such as the fact that circulating vitamin $\mathrm{D}$ has a half-life of $\sim 2-3$ weeks. ${ }^{32}$ Serial measurement of levels may be of value; however, we did not obtain serial measurement 
of serum $25(\mathrm{OH}) \mathrm{D}$ due to the inconvenience and cost of the test. We do not know whether testing at onset of illness or knowing the mean value during the study would show a more accurate association with the course of illness and treatment outcomes. Second, we assumed that the severity of illness using APACHE-II scores could be applied for use in the medical unit. Normally, this score is extensively used only in intensive care units; however, we were not aware of any other suitable severity scores for ward patients, and this score has been used in this population previously. ${ }^{33}$ Finally, the overall mortality in our study was fairly low, which caused a low statistical precision in detecting a difference in mortality between the vitamin D deficient and non-deficient, and limited the number of variables that could be included in the logistic regression analysis.

Nevertheless, our study is one of the few studies that investigated vitamin D status in patients with severe sepsis admitted to medical wards. Moreover, there may be some differences in sun exposure levels between our country and the Western populations, from where most data have been collected; those differences may prove to be significant in a future comparative study. Aside from a high prevalence of vitamin D deficiency in patients with severe sepsis, our study also identified that severe vitamin D deficiency was associated with worse clinical outcomes. This particular group of patients may benefit from vitamin D treatment. Future research with a larger sample size in similar or different cohorts to confirm our findings regarding the impact of low vitamin D levels is important. This information will serve as a foundation for detailing the prevalence of vitamin $\mathrm{D}$ deficiency and outcomes in patients with severe sepsis.

\section{Acknowledgments}

The authors would like to thank Professor Peter Dodek, Department of Medicine, University of British Columbia, Canada for his encouragement in conducting the research; Associate Professor Siriwan Tangjitgamol, Faculty of Medicine Vajira Hospital, Navamindradhiraj University for her advice in scientific content and manuscript preparation; and Jason D Cullen, Vajira Scientific Editing Center, Faculty of Medicine Vajira Hospital for editing the manuscript. This work was supported in part by a grant from the Research Fund of Faculty of Medicine Vajira Hospital, Navamindradhiraj University, Bangkok, Thailand. The study sponsor had no role in any steps of the study.

Trial Registration Identifier: Thai Clinical Trials Registry (TCTR 20151130001; http://www.clinicaltrials.in.th/index.

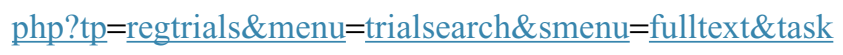
$=\underline{\text { search } \& \operatorname{task} 2=\text { view } 1 \& i d=1629}$ ).

\section{Author contributions}

All authors contributed toward data analysis, drafting and critically revising the paper and agree to be accountable for all aspects of the work.

\section{Disclosure}

The authors report no conflicts of interest in this work.

\section{References}

1. Holick MF. Resurrection of vitamin D deficiency and rickets. J Clin Invest. 2006;116(8):2062-2072.

2. Dusso AS, Brown AJ, Slatopolsky E. Vitamin D. Am J Physiol Renal Physiol. 2005;289(1):F8-F28.

3. Holick MF. Vitamin D deficiency. N Engl J Med. 2007;357(3):266-281.

4. Van den Berghe G, Van Roosbroeck D, Vanhove P, Wouters PJ, De Pourcq L, Bouillon R. Bone turnover in prolonged critical illness: effect of vitamin D. J Clin Endocrinol Metab. 2003;88(10):4623-4632.

5. Leaf DE, Raed A, Donnino MW, Ginde AA, Waikar SS. Randomized controlled trial of calcitriol in severe sepsis. Am J Respir Crit Care Med. 2014;190(5):533-541.

6. Liu PT, Stenger S, Li H, et al. Toll-like receptor triggering of a vitamin D-mediated human antimicrobial response. Science. 2006; 311(5768):1770-1773.

7. Turkoglu M, Aygencel G, Dizbay M, et al. Is vitamin D deficiency associated with development of Acinetobacter baumannii infections in critically ill patients? J Crit Care. 2013;28(5):735-740.

8. Moromizato T, Litonjua AA, Braun AB, Gibbons FK, Giovannucci E, Christopher KB. Association of low serum 25-hydroxyvitamin D levels and sepsis in the critically ill. Crit Care Med. 2014;42(1):97-107.

9. de Haan K, Groeneveld AB, de Geus HR, Egal M, Struijs A. Vitamin D deficiency as a risk factor for infection, sepsis and mortality in the critically ill: systematic review and meta-analysis. Crit Care. 2014;18(6):660.

10. Upala S, Sanguankeo A, Permpalung N. Significant association between vitamin D deficiency and sepsis: a systematic review and meta-analysis. BMC Anesthesiol. 2015;15:84.

11. Braun AB, Litonjua AA, Moromizato T, Gibbons FK, Giovannucci E, Christopher KB. Association of low serum 25-hydroxyvitamin D levels and acute kidney injury in the critically ill. Crit Care Med. 2012;40(12): 3170-3179.

12. Giovannucci E, Liu Y, Hollis BW, Rimm EB. 25-Hydroxyvitamin D and risk of myocardial infarction in men: a prospective study. Arch Intern Med. 2008;168(11):1174-1180.

13. Lucidarme O, Messai E, Mazzoni T, Arcade M, du Cheyron D. Incidence and risk factors of vitamin $\mathrm{D}$ deficiency in critically ill patients: results from a prospective observational study. Intensive Care Med. 2010;36(9):1609-1611.

14. Lee P, Eisman JA, Center JR. Vitamin D deficiency in critically ill patients. N Engl J Med. 2009;360(18):1912-1914.

15. McKinney JD, Bailey BA, Garrett LH, Peiris P, Manning T, Peiris AN. Relationship between vitamin D status and ICU outcomes in veterans. J Am Med Dir Assoc. 2011;12(3):208-211.

16. Venkatram S, Chilimuri S, Adrish M, Salako A, Patel M, Diaz-Fuentes G. Vitamin D deficiency is associated with mortality in the medical intensive care unit. Crit Care. 2011;15(6):R292.

17. Higgins DM, Wischmeyer PE, Queensland KM, Sillau SH, Sufit AJ, Heyland DK. Relationship of vitamin D deficiency to clinical outcomes in critically ill patients. JPEN J Parenter Enteral Nutr. 2012;36(6):713-720.

18. Braun AB, Gibbons FK, Litonjua AA, Giovannucci E, Christopher KB. Low serum 25-hydroxyvitamin $\mathrm{D}$ at critical care initiation is associated with increased mortality. Crit Care Med. 2012;40(1):63-72.

19. Han J, Ziegler T. Vitamin D supplementation in sepsis and critical illness: where are we now? Am J Respir Crit Care Med. 2014;190:483-487. 
20. Amrein K, Schnedl C, Holl A, et al. Effect of high-dose vitamin D3 on hospital length of stay in critically ill patients with vitamin D deficiency: the VITdAL-ICU randomized clinical trial. JAMA. 2014;312(15):1520-1530.

21. Chailurkit LO, Aekplakorn W, Ongphiphadhanakul B. Regional variation and determinants of vitamin $\mathrm{D}$ status in sunshine-abundant Thailand. BMC Public Health. 2011;11:853.

22. Nimitphong H, Chailurkit LO, Chanprasertyothin S, Sritara P, Ongphiphadhanakul B. The association of vitamin D status and fasting glucose according to body fat mass in young healthy Thais. BMC Endocr Disord. 2013;13:60.

23. Dellinger RP, Levy MM, Rhodes A, et al. Surviving Sepsis Campaign: international guidelines for management of severe sepsis and septic shock, 2012. Intensive Care Med. 2013;39(2):165-228.

24. Holick MF, Binkley NC, Bischoff-Ferrari HA, et al. Evaluation, treatment, and prevention of vitamin D deficiency: an Endocrine Society clinical practice guideline. J Clin Endocrinol Metab. 2011;96(7):1911-1930.

25. Looker AC, Johnson CL, Lacher DA, Pfeiffer CM, Schleicher RL, Sempos CT. Vitamin D Status: United States, 2001-2006. Hyattsville, MD: NCHS; 2011

26. Spiro A, Buttriss JL. Vitamin D: an overview of vitamin D status and intake in Europe. Nutr Bull. 2014;39(4):322-350.
27. Nair P, Lee P, Reynolds C, et al. Significant perturbation of vitamin D-parathyroid-calcium axis and adverse clinical outcomes in critically ill patients. Intensive Care Med. 2013;39(2):267-274.

28. Chen Z, Luo Z, Zhao X, et al. Association of vitamin D status of septic patients in intensive care units with altered procalcitonin levels and mortality. J Clin Endocrinol Metab. 2015;100(2):516-523.

29. Chapuy MC, Preziosi P, Maamer M, et al. Prevalence of vitamin $\mathrm{D}$ insufficiency in an adult normal population. Osteoporosis Int. 1997; 7(5):439-443.

30. Ala-Kokko TI, Mutt SJ, Nisula S, et al. Vitamin D deficiency at admission is not associated with 90-day mortality in patients with severe sepsis or septic shock: observational FINNAKI cohort study. Ann Med. 2016;48(1-2):67-75.

31. Quraishi SA, Camargo CA Jr. Vitamin D in acute stress and critical illness. Curr Opin Clin Nutr Metab Care. 2012;15(6):625-634.

32. Holick MF. Vitamin D status: measurement, interpretation, and clinical application. Ann Epidemiol. 2009;19(2):73-78.

33. Goel A, Pinckney RG, Littenberg B. APACHE II predicts long-term survival in COPD patients admitted to a general medical ward. J Gen Intern Med. 2003;18(10):824-830.
International Journal of General Medicine

\section{Publish your work in this journal}

The International Journal of General Medicine is an international peer-reviewed open-access journal that focuses on general and internal medicine, pathogenesis, epidemiology, diagnosis, monitoring and treatment protocols. The journal is characterized by the rapid reporting of reviews, original research and clinical studies across all disease areas.

\section{Dovepress}

The manuscript management system is completely online and includes a very quick and fair peer-review system, which is all easy to use. Visit http://www.dovepress.com/testimonials.php to read real quotes from published authors.

Submit your manuscript here: https://www.dovepress.com/international-journal-of-general-medicine-journal 